\title{
Rehabilitation Following UCL Repair with Internal Brace
}

\author{
Kevin E Wilk ${ }^{1,2 *}$, Christopher A Arrigo ${ }^{3,4}$ and Rebekah J Arrigo ${ }^{5}$ \\ ${ }^{1}$ Associate Clinical Director, Champion Sports Medicine-Physiotherapy Associates, USA \\ ${ }^{2}$ Director of Rehabilitative Research, American Sports Medicine Institute, USA \\ ${ }^{3}$ Owner, Clinical Director, Advanced Rehabilitation, USA \\ ${ }^{4}$ Special Consultant for Throwing Injuries, Lafayette Medical Director, USA \\ ${ }^{5}$ Graduate Assistant Athletic Trainer, Tennessee Tech University, USA
}

*Corresponding author: Kevin Wilk, Associate Clinical Director, Champion Sports Medicine-Physiotherapy Associates, Director of Rehabilitative Research, American Sports Medicine Institute, Birmingham, Alabama, USA

Keywords: Baseball; Elbow, Pitching; Surgery; Throwing; UCL; Ulnar Collateral Ligament

\section{Introduction}

Elbow injuries in the overhead athlete, particularly baseball pitchers, continue to increase in frequency because of extreme repetitive valgus stress [1-4]. This repetitive stress results in ulnar collateral ligament (UCL) insufficiency which produces elbow pain, medial joint laxity, and an inability to throw.16 Pitchers are the most injured players in Major League Baseball and elbow injuries account for $22-26 \%$ of pitching injuries $[1,5,6]$. The risk factors related to sustaining a pitching related UCL injury are pitching when fatigued, a high pitch volume, improper mechanics, and repetitive throwing at maximal effort in the youth player and throwing a high number of pitches at peak velocity in the professional athlete [7]. The current preferred surgical treatment for most UCL tears that fail conservative management is a reconstruction using one of several autogenous grafts. [8] Extensive follow-up data on UCL reconstructions with a minimum 2-year follow-up shows that just $83 \%$ of the athletes undergoing reconstruction were able to return to the same level of play or higher and that on average return to competition took 11.6 months [9].

However, recent technological advances have sparked renewed interest in repair of the UCL augmented by an internal brace
(Internal Brace; Arthrex Inc) in a search for a surgical option that would allow a faster recovery than what is typical following UCL reconstruction. Repair of the UCL with internal brace is a direct repair of the native ligament with a spanning tape dipped in collagen (Internal Brace) anchored on each end of the UCL [10]. (Figure 1) Two $3.5 \mathrm{~mm}$ Swive Locks spanned with a $2 \mathrm{~mm}$ piece of Fiber Tape (Arthrex, Inc. 1370 Creekside Blvd., Naples, FL, 34108) and size 0 nonabsorbable sutures are used to repair the native ligament back to its anatomic origin and insertion ensuring that tension of the Fiber Tape matches that of the native UCL during range of motion (ROM). A UCL repair with internal brace is reserved for use in cases of partial or complete tears at the origin or insertion of the UCL with good ligament tissue and low-grade mid-substance partial UCL tears [10]. In patients with chronic, attritional damage to the UCL and associated loss of elbow joint stability, reconstruction remains the most appropriate surgical intervention $[8,9,11,12]$. The decision to perform a surgical repair of the UCL, rather than a reconstruction, can only be made intra-operatively from direct visual assessment of the UCL. 


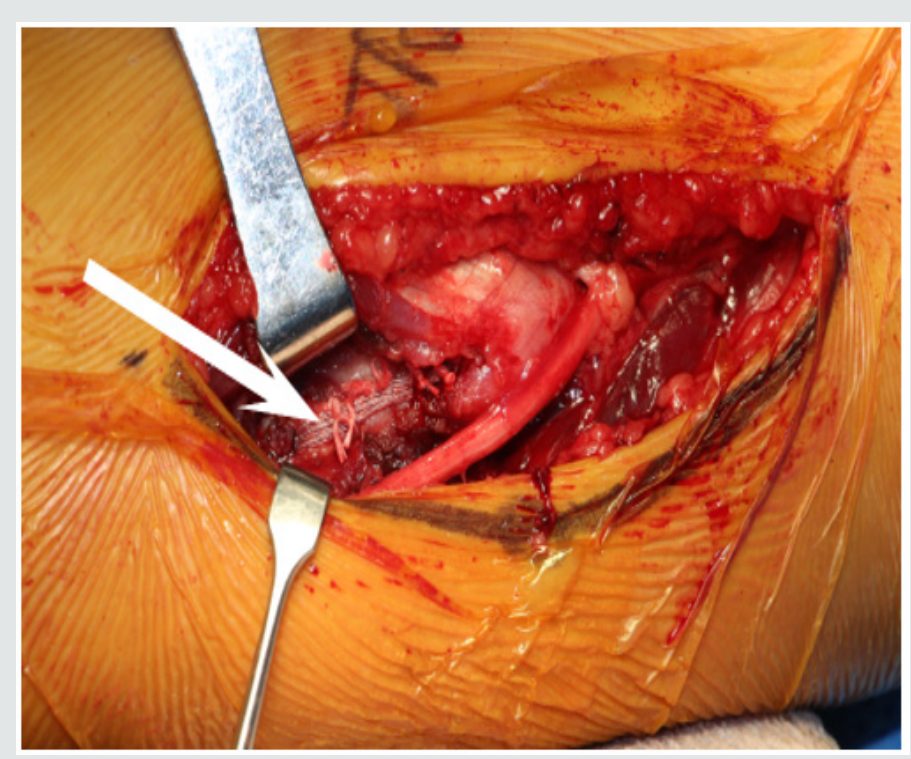

Figure 1: The UCL repair with the internal brace inserted within the ligament.

\section{Rehabilitation Guidelines}

Rehabilitation after UCL repair with internal brace surgery is accomplished via a sequential and progressive 5 phased approach, designed to return the athlete to their previous level or higher as quickly and safely as possible [13-15] (Table 1). Initially rehabilitation interventions are designed to minimize the effects of immobilization, facilitate early healing of the UCL, re-establishing pain-free ROM, reduce pain and inflammation, and retard muscular atrophy. Early limited passive elbow/forearm ROM exercises and grade I/II joint mobilizations are incorporated in conjunction to neuromodulate pain, promote articular cartilage nutrition and aide in the synthesis, alignment, and organization of collagen tissue [16-19], [20-25]. Local modalites, including Cryotherapy, electrical stimulation and Class IV deep tissue laser are used to control pain, inflammation, speed healing of the incision and increase nitrous oxide in the healing tissue [26]. Pain free, submaximal isometrics are used to initiate muscle activation and retard atrophy for all planes of elbow, forearm, wrist and shoulder movements. Shoulder external rotation (ER) and internal rotation (IR) isometrics are performed with caution and must be completely pain free. Rhythmic stabilization and neuromuscular control drills for shoulder, elbow and wrist along with seated scapular and postural exercises are also introduced early in the rehabilitation process.

Table 1: Postoperative Rehabilitation After Ulnar Collateral Ligament Repair with Internal Brace.

\begin{tabular}{|c|}
\hline Goals: Protect healing tissue; reduce pain and inflammation; retard muscle atrophy; full wrist (range of motion) ROM \\
\hline Day of Surgery \\
\hline Elbow ROM brace locked at $90^{\circ}$ for 7 days \\
\hline Passive ROM (PROM) wrist and hand \\
\hline Post-op Day 1 and 2: Add (all performed in locked elbow brace) \\
\hline Shoulder PROM: flexion, ER, and IR to tolerance \\
\hline Pendulum exercises \\
\hline Wrist flexor/extensor stretching \\
\hline Putty/gripping exercises \\
\hline Post-op Day 3 through 7 (all exercises performed in locked elbow brace) \\
\hline 1. Continue previous exercises, advancing PROM as tolerated \\
\hline 2. Add the following exercises \\
\hline a. Shoulder isometrics: ER, IR, abduction, flexion, and extension \\
\hline b. Scapular strengthening (seated neuromuscular control drills with manual resistance) \\
\hline II Controlled Mobility (Weeks 2-5) \\
\hline Goals: Gradually restore elbow joint ROM; improve muscular strength and endurance; normalize joint arthrokinematics \\
\hline Beginning Week 2 (Day 8) \\
\hline Progress Elbow ROM brace to $30-110^{\circ}$ \\
\hline Begin elbow PROM and AAROM 30-110 \\
\hline
\end{tabular}




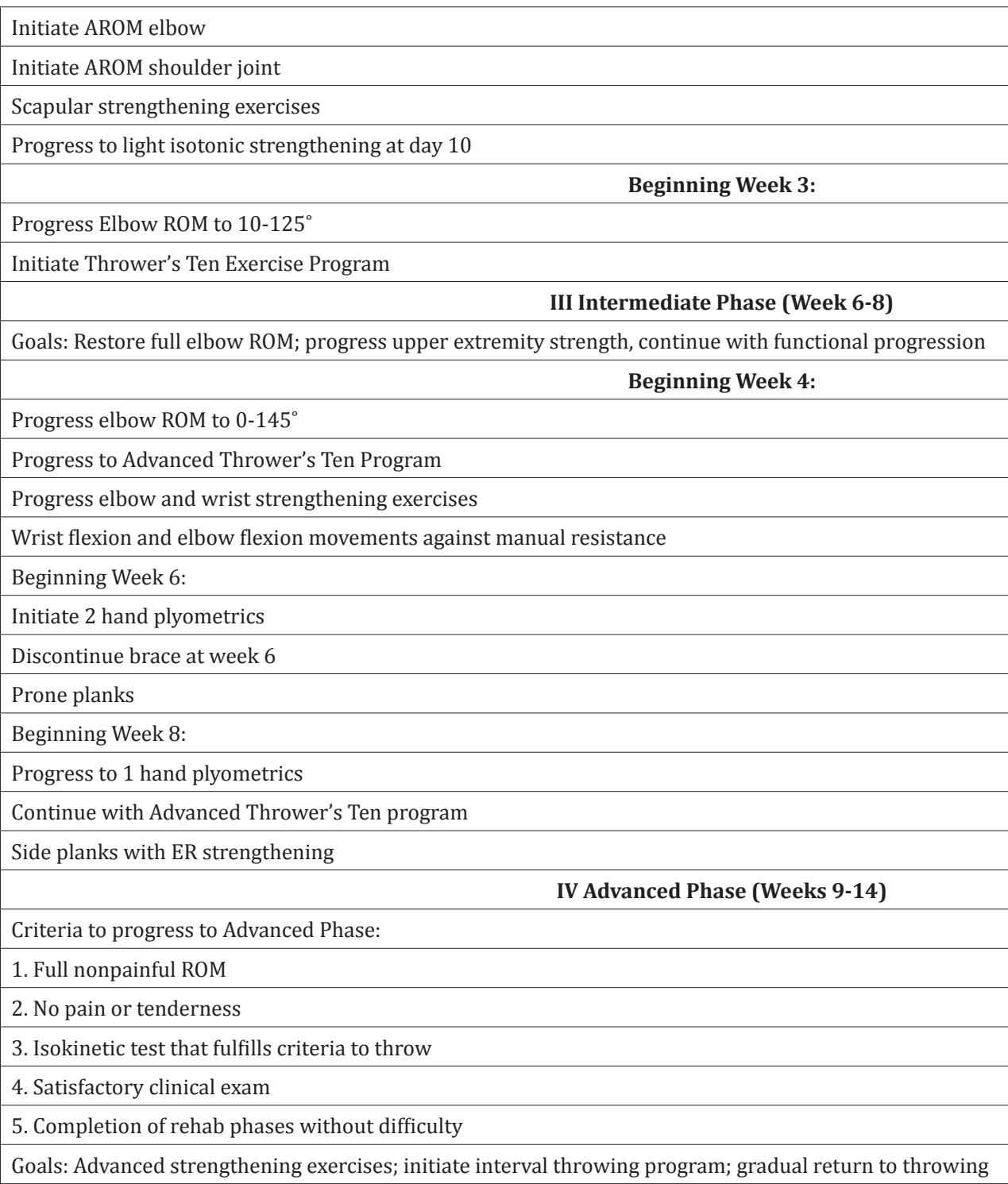

\section{Beginning Week 9:}

Continue all strengthening exercises

Advanced Thrower's Ten program

Plyometrics program ( 1 and 2 hand program)

Seated chest press machine

Beginning Week 10:

Initiate interval hitting program at (week 10) Seated rowing

Biceps/Triceps strengthening

\section{Beginning Week 11-16:}

Initiate Interval Throwing Program Phase 1- Long Toss (week 12)

Continue all exercises as in week 9-10

Beginning week 16-20:

Initiate Interval Throwing Phase 2 (Off the mound) when Phase 1 is complete and athlete is ready

Continue Advanced Thrower's Ten program

Continue Plyometrics

Continue ROM and Stretching Programs

\section{Return to Play Phase (weeks 14+):}

Goals: Gradual return to competitive throwing; continue all exercises and stretches 


\begin{tabular}{l|l|}
\hline \multicolumn{1}{|c|}{ Week 20+: } \\
\hline Initiate gradual return to competitive throwing \\
\hline Perform dynamic warm-ups and stretches \\
\hline Continue thrower's ten program \\
\hline Return to competition when athlete is ready (physician decision) \\
\hline $\begin{array}{l}\text { Note: }{ }^{* *} \text { Each athlete may progress through ITP at different rates/pace Should complete } 0-90 \mathrm{ft} \text { within } 3 \text { weeks of starting ITP and complete } 120 \mathrm{ft} \text { within } \\
8 \text { weeks }\end{array}$ \\
\hline
\end{tabular}

The controlled mobility phase runs for a total of 3 weeks starting at the second week after surgery and focuses on a stepped restoration in elbow ROM (outlined in Table 1), improved muscular strength/endurance, and normalizing joint arthrokinematics. Active-assisted, active, and passive ROM exercises, as well as more aggressive joint mobilizations, are all incorporated for the elbow, forearm and wrist with the primary goal to achieve full elbow extension and minimize the risk of developing an elbow flexion contracture [26-29]. Elbow flexion contractures are the most common postoperative complication following elbow surgery and must be diligently avoided. At any sign of flexion contracture, we find using a low load-long duration (LLLD) stretch in conjunction with joint mobilization and stretching to be extremely beneficial for regaining full elbow extension. A light resistance exercise band (Theraband CLX Performance Health, 1245 Home Ave, Akron, OH 44310 ) is applied to the wrist and used to place a LLLD stretch on the anterior elbow structures for 12-15 minutes, for a total of 60 minutes a day. (Figure 2) Strengthening exercises at this point are performed beginning with concentric and progressing to eccentric muscle contractions with the focus placed on a comprehensive strengthening program for the throwing athlete, such as the Thrower's Ten Program [30,31].

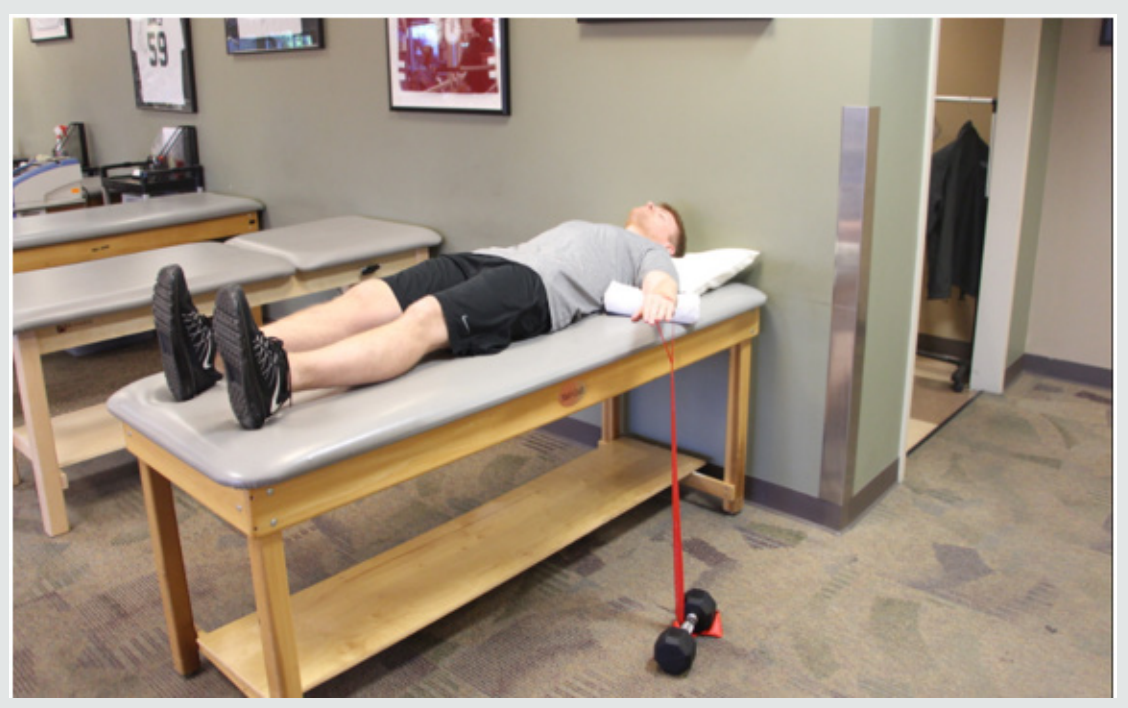

Figure 2: Low load-long duration stretching to improve elbow extension. A low intensity stretch is applied for 10-12 minutes. Note that the elbow is pronated and the shoulder is internally rotated to lock the humerus and prevent compensation.

The intermediate phase is from postoperative week 6 to 8 and emphasizes the maintenance of joint mobility, improving muscular strength, endurance, neuromuscular control of the elbow complex, and continuing with a functional progression of activity. Stretching, flexibility and mobilizations are used to maintain full motion with a particular focus on elbow extension and forearm pronation flexibility. At 4 weeks the athlete is progressed to the advanced thrower's 10 program to place greater demands on the posterior shoulder and scapular muscles [32]. Neuromuscular control manual resistance exercises are incorporated for both the shoulder and elbow, proprioceptive neuromuscular facilitation, rhythmic stabilizations, and slow reversal hold techniques. 2-handed plyometrics are introduced 6 weeks following surgery progressing to 1 -hand exercises 2 weeks later. The fourth phase of UCL repair rehabilitation is the advanced phase which runs from weeks 9 to 14 and is specifically designed to increase strength, power, endurance, and neuromuscular control to prepare for a return to sports using strengthening activities that emphasize high speed, eccentric contractions, and plyometrics. Elbow flexion exercises here emphasize high speed eccentric control training elbow deceleration. Weight machine exercises are begun 10 weeks after surgery and include, seated chest press, seated rowing, and front latissimus dorsi pull-downs. A hitting program is permitted at week 10 and an interval throwing program 11 weeks after surgery if the athlete meets the objective criteria for throwing. Reinold et al. [33] provides the best description of sports specific interval programs. Pitchers generally are able to advance to throwing off of a mound 8 weeks after they begin a throwing program. 
The return to activity phase is the last part of the process and emphasizes a proper dynamic warm-up, continued exercise loads and managing the progression back to unrestricted activity and competitive throwing $[34,35]$. The general time frame to return to play following a UCL repair with internal brace is approximately 5 months. Functional testing can aide the return to play decision process. We use the prone ball drop test, developed by the senior author (KEW) which utilizes a $1 \mathrm{~kg}$ ( 2 pound) plyoball with the patient prone, shoulder abducted to $90^{\circ}$, and elbow extended. The patient is instructed to perform as many ball drops and catches as possible in a 30 second timeframe, comparing successful cathese bilaterally seeking a goal of $110 \%$ for the throwing side (Figure 3). At our center, 350 UCL repairs with internal brace have been performed. Of these, 1-year follow-up data is available for 79 throwers, showing $98 \%$ of the 1-year follow ups returned to their pre-injury level of activity.

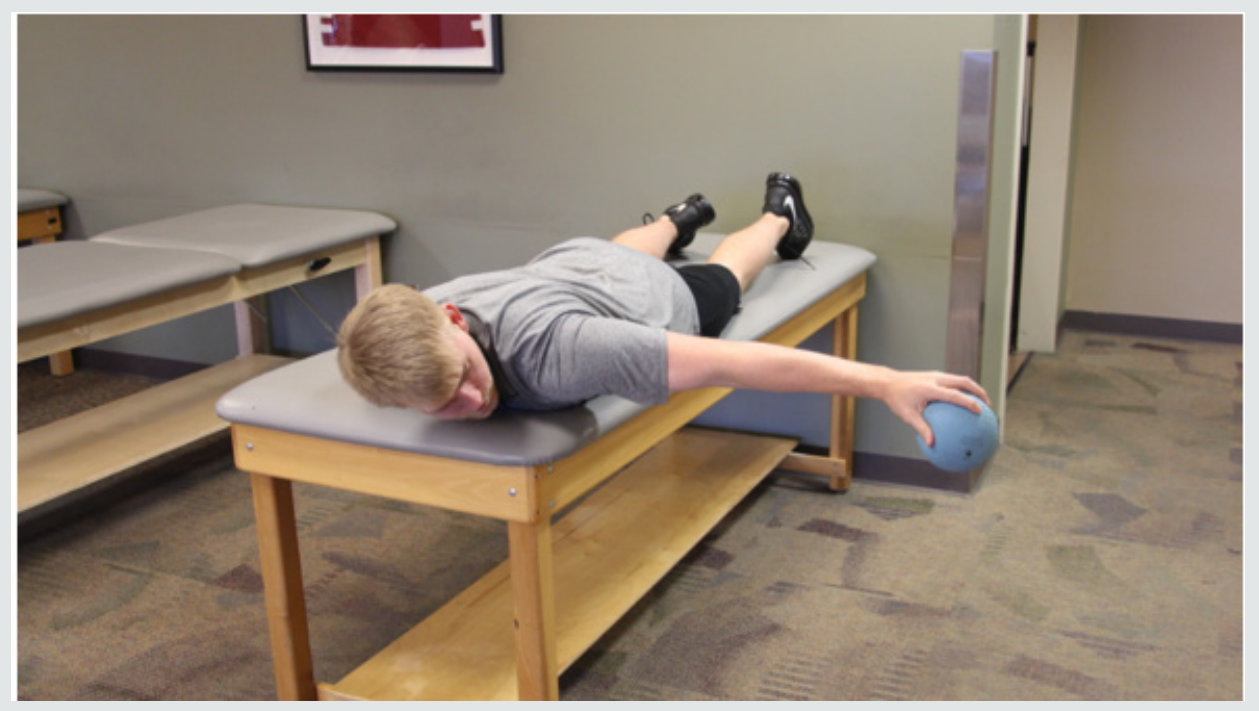

Figure 3: Ball Drop Test: Patient is in prone position on table with 2 LB plyoball in hand performs ball drops \& catches for 30 second with the shoulder abducted to $90^{\circ}$ and elbow extended.

\section{Summary}

The UCL is a frequently injured in overhead athletes and these injuries continue to climb in number in youth athletes. Surgical repair of the UCL with internal brace is a viable option in athletes who meet specific findings at the time of surgery. The rehabilitation of this unique surgical procedure has been presented based on our experience treating in excess of 350 athletes over the past 3 years. The average time required for an athlete to return to participation in our cohort is 7 months which is approximately 5 months less than average return to play times after UCL reconstruction surgery. Long-term results of this surgery and rehabilitation program are still needed but our initial experience is extremely promising.

\section{References}

1. Conte SA, Fleisig GS, Dines JS, Wilk KE, Aune KT, et al. (2015) Prevalence of Ulnar Collateral Ligament Surgery in Professional Baseball Players. Am J Sports Med 43(7): 1764-1769.

2. Fleisig GS, Escamilla RF (1996) Biomechanics of the elbow in the throwing athlete, Op Tech Sports Med 4(2): 62-68.

3. Hodgins JL, Vitale M, Arons RR (2016) Epidemology of Medial Collateral Ligament Reconstruction: A 10 year Study in New York State. Am J Sports Med 44(3): 729-734.

4. Petty DH, Andrews JR, Fleisig GS, Cain EL (2004) Ulnar Collateral Ligament Reconstruction in High School Baseball Players, Am J Sports Med 32(5): 1158-1164.

5. Conte S, Requa RK, Garrick JG (2001) Disability days in Major League Baseball. Am J Sports Med 29(4): 431-436.
6. Posner M, Cameron KL, Wolf JM, Belmont PJ Jr, Owens BD (2011) Epidemiology of Major League Baseball injuries. Am J Sports Med 39(8): 1676-1680.

7. Chalmers PN, Erickson BJ, Ball B, Romeo AA, Verma NN (2016) Fastball Pitch Velocity Helps Predict Ulnar Collateral Ligament Reconstruction in Major League Baseball Pitchers. Am J Sports Med 44(8): 2130-2135.

8. Conway JE, Jobe FW, Glousman RE, Pink M (1992) Medial instability of the elbow in throwing athletes: treatment by repair or reconstruction of the ulnar collateral ligament. J Bone Joint Surg Am 74(1): 67-83.

9. Cain EL Jr, Andrews JR, Dugas JR, Wilk KE, McMichael CS, et al. (2010) Outcome of ulnar collateral ligament reconstruction of the elbow in 1281 athletes: results in 743 athletes with minimum 2-year follow-up. Am J Sports Med 38(12): 2426-2434.

10. Dugas JR, Walters BL, Beason DP, Fleisig GS, Chronister JE (2016) Biomechanical Comparison of Ulnar Collateral Ligament Repair With Internal Bracing Versus Modified Jobe Reconstruction. Am J Sports Med 44(3): 735-741.

11. Azar FM Andrews, JR, Wilk KE, Groh D (2000) Operative treatment of unlar collateral ligament injuries of the elbow in athletes. Am J Sports Med 28(1): 16-23.

12. Jobe FW, Stark H, Lombardo SJ (1986) Reconstruction of the ulnar collateral ligament in athletes. J Bone Joint Surg AM 68(8): 1158-1163.

13. Wilk KE, Arrigo CA, Andrews JR (2016) Rehabilitation of the Overhead Throwing Athlete: There is More to It Than Just External Rotation/ Internal Rotation Strengthening. PMR, 8(3suppl): S78-90.

14. Wilk KE, Macrina LC, Cain EL, Dugas JR, Andrews JR (2012) Rehabilitation of the Overhead Athlete's Elbow, Sports Health 4(5): 404-414.

15. Wilk K, Macrina L, Fleisig G, Porterfield R, Simpson C, et al. (2011) Rotational Motion to Shoulder Injuries in Professional Baseball Pitchers, Am J Sports Med 39(2): 329-335. 
16. Coutts R, Rote C, Kaita J (1981) The role of continuous passive motion in the rehabilitation of the total knee patient Clin Orthop Relat Res 159: 126-132.

17. Dehne E, Troy R (1971) The treatment of joint injuries by immediate mobilization based upon the spiral adaption concept, Clin Orthop Relat Res 77: 218-232.

18. Noyes FR, Mangine RE, Barber SE (1987) Early knee motion after open and arthroscopic anterior cruciate ligament reconstruction Am J Sports Med 15(2): 149-160.

19. (1954) Perkins G: Rest and motion. J Bone Joint Surg Br 35: 521-539.

20. Salter RB, Hamilton HW, Wedge JH (1980) Clinical application of basic research on continuous passive motion on healing full thickness defects in articular cartilage. J Bone Joint Surg Am 62: 1232-1251.

21. Salter RB, Hamilton HW, Wedge JH (1984) Clinical application of basic research on continuous passive motion for disorders and injuries of synovial joints: a preliminary report of a feasibility study, J Orthop Res 1(3): 325-342.

22. Sapega AA, Quedenfeld TC, Moyer RA, Butler RA (1976) Biophysical factors in range of motion exercise, Arch Phys Me Rehabil 57: 122-126.

23. Thompson WH, Jobe FW, Yacum LA, Pink M (2001) Ulnar collateral ligament reconstruction in athletes: muscle splitting approach without transposition of the ulnar nerve, J Shoulder Elbow Surg 10(2): 152-157.

24. Warren CG, Lehmann JF, Koblanski JN (1971) Elongation of rat tail tendon: effect of load and temperature. Arch Phys Med Rehabil 52: 465474.

25. Warren CG, Lehmann JF, Koblanski JN (1976) Heat and stretch procedures: an evaluation using rat tail tendon, Arch Phys Med Rehabil 57(3): 122-126.
26. Borsa PA, Larkin KA, True JM (2013) Does phototherapy enhance skeletal muscle contractile function and postexercise recovery? A systematic review. J Athletic Training 48(1): 57-67.

27. Akeson WH, Amiel D, Woo SLY (1980) Immobilization effects on synovial joints: the pathome chanics of joint contracture Biorheology 17(1-2): 95-107.

28. Green DP, McCoy H (1979) Turnbuckle orthotic correction of elbow flexion contractures. J Bone Joint Surg Am 61(7): 1092-1095

29. Wilk, KE Arrigo CA, Andrews JR (1993) Rehabilitation of the elbow in the throwing athlete J Orthop Sports Phys Ther 17(6): 305-317.

30. Wilk KE, Arrigo CA (1992) An integrated approach to upper extremity exercises. Orthop Phys Ther Clin North Am 1: 337-360.

31. Wilk KE, Andrews JR, Arrigo C (2001) Preventive and Rehabilitative Exercises for the Shoulder and Elbow. 6th ed. Birmingham, AL: American Sports Medicine Institute.

32. Wilk KE, Yenchak AJ, Arrigo CA, Andrews JR (2011) The Advanced Thrower's Ten Program: A New Exercise Series for Enhanced Dynamic Shoulder Control in the Overhead Throwing Athlete, Phys Sports med 39(4): 90-97.

33. Reinhold MM, Wilk KE, Reed J, et al (2002) Interval sport programs: guidelines for baseball, tennis and golf. J Orthop Sports Phys Ther 32(6): 293-298.

34. Kandemir U, Fu FH, McMahon PJ (2002) Elbow injuries, Curr Opin Rheumatol 14(2): 160-167.

35. Lyman SL, Fleisig GS, Osinski ED (1998) Incidence and Determinants of Arm Injury in Youth Baseball Pitchers: A Pilot Study. Med Sci Sports Exerc 30: S4.

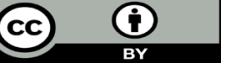

This work is licensed under Creative Commons Attribution 4.0 License

To Submit Your Article Click Here:

Submit Article

DOI: $10.32474 / O S M O A J .2019 .03 .000151$

Orthopedics and Sports Medicine
Open Access Journal
Assets of Publishing with us
- Global archiving of articles
- Immediate, unrestricted online access
- Rigorous Peer Review Process
- Authors Retain Copyrights
- Unique DOI for all articles

